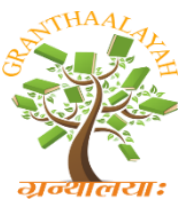

INTERNATIONAL JOURNAL OF RESEARCH GRANTHAALAYAH A knowledge Repository

Science

\title{
BIOMETRIC ATTENDANCE MONITORING SYSTEM OF CAGAYAN STATE UNIVERSITY - LASAM CAMPUS, PHILIPPINES
}

\author{
Jake G. Maggay ${ }^{* 1}$ \\ ${ }^{*}$ College of Information and Computing Sciences, Cagayan State University - Lasam Campus, \\ Philippines
}

DOI: https://doi.org/10.29121/granthaalayah.v5.i2.2017.1704

\begin{abstract}
The study aimed to develop a fully customized Biometric Attendance Monitoring System (BAMS) of Cagayan State University - Lasam Campus, Philippines (CSU - Lasam) using biometric fingerprint reader to facilitate the monitoring of employees' attendance. This study followed the framework of Design Science Research for Information Systems, thus, the researcher identified the problems and issues encountered in the monitoring of attendance, defined the objectives of the study, designed and developed the system, deployed and tested, and presented the result of the study. A combination of Visual Basic 6.0 as the programming language and MS Access as the Database Management Systems were used in the development of the system.Thus, the overall functionality of the BAMS enables the users to enter data, change and manipulate the data, get information, and store the data and the information. Username and password is no longer needed since all transactions use unique fingerprint to validate users. Furthermore, the BAMS greatly contributes in giving employees' ease and improving work values. Likewise, the BAMS is essential in achieving good governance because it helps track day-to-day attendance of the employees.
\end{abstract}

Keywords: Biometric; Attendance; Computerized System; Monitoring System; Fingerprint Scanner.

CITE THIS ARTICLE: Jake G. Maggay. (2017). "BIOMETRIC ATTENDANCE MONITORING SYSTEM OF CAGAYAN STATE UNIVERSITY- LASAM CAMPUS, PHILIPPINES". International Journal of Research - Granthaalayah, 5(2), 67-79. https://doi.org/10.29121/granthaalayah.v5.i2.2017.1704.

\section{Introduction}

Many industries and institutions are already using biometric in monitoring the attendance of employees which really saves time and prevents time theft that leads to cost saving. Biometric technology offers advanced verification of employees because it identifies people through 
physical measurements of unique human characteristics such as fingerprints. Employee attendance verification is a major use of biometrics today.

Furthermore, biometric is the tool which measures individual's unique physical or behavioral characteristics to recognize or authenticate their identity and it is most secure and convenient authentication tool.

Individual's unique physical or behavioral characteristics cannot be borrowed, stolen, or forgotten and forging one is practically impossible. Common physical biometrics includes fingerprints, hand or palm geometry, retina, iris, and facial characteristics.

Moreover, biometric technologies capitalize upon unique, permanent, and scanable human characteristics that is unique and no other person shares. This characteristic should also remain the same overtimes. All biometric devices take a number of measurements from an individual then digitally process the result of these measurements and save this representation of the individual's traits into a template. Templates are then stored in a database associated with the device or in a smartcard given to the individual (Salh, et. al, 2015).

The researcher aims to develop a fully customized Biometric Attendance Monitoring System (BAMS) for Cagayan State University - Lasam Campus, Philippines (CSU-Lasam) to strictly monitor the attendance of employees as one way of improving the services of the Campus. Moreover, this would help the government in reducing the expenses by eliminating time theft and in achieving good governance. Likewise, the system might influence the employees to become punctual and more responsive in performing tasks based on the prescribed number of working hours.

\section{Conceptual Framework}

The study is guided with the Input-Process-Output (IPO) model to design and develop a customized BAMS that enables the users to enter data, process data, produce information, and store them in a database with user-friendly interface between the users and the system.
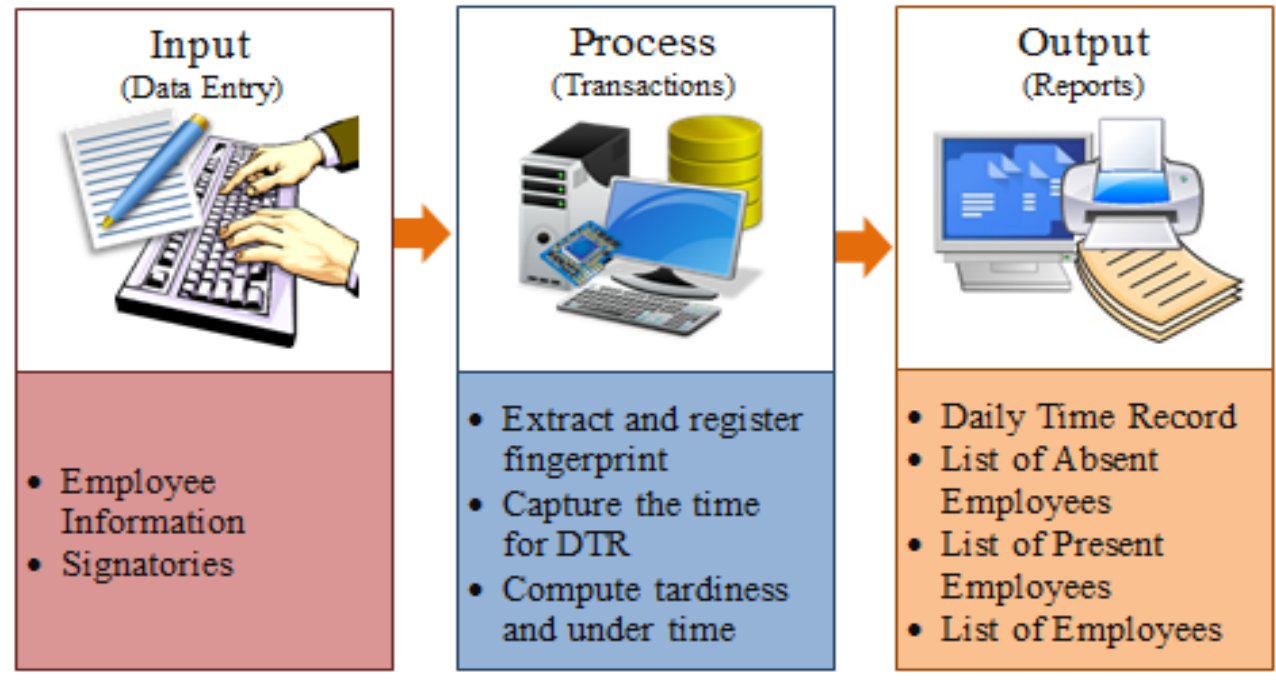

Figure 1: The Conceptual Model 


\section{Statement of the Objective}

The general objective of the study is to develop a fully customized BAMS based on the status of the manual monitoring of attendance in the campus and specifically to:

1) replace the manual monitoring of attendance

2) enforce security in monitoring the employees' attendance

3) prevent employee time theft

4) contribute in the achievement of good governance.

\section{Materials and Methods}

\subsection{Study Design}

The researcher used the Design Science Research (DSR) for Information Systems (IS) following the six steps.

First, the researcher identified the problems in monitoring the attendance of employees through series of interview;

Second, the researcher defined the objective of the study based on the problems identified and that is to develop a fully customized Biometric Attendance Monitoring System (BAMS) that will support the monitoring of attendance;

Third, the researcher analyzed the requirements based on the identified problems and the objective, then created the design of the desired interface and functionality of the system which involves modeling and flowcharting. Based on the created design, the researcher developed each feature of the system which involves programming or coding and preliminary testing, and integrated all the features for testing and for deployment;

Fourth, the researcher deployed the finished system for production or use. It involves end-user training and support, management of change, and data conversions. Further, it involves experiment or testing and series of refinements to minimize or eliminate unfavorable impacts;

Fifth, in evaluating the functionality and impact of the BAMS, the researcher observed the actual situation as the users use it;

Lastly, the researcher makes the availability of this paper to diffuse or communicate the problem and its importance, the artifact which is the BAMS, its utility, novelty, design and its success to the researcher and other audience such as practicing professionals. Moreover, the researcher deposited the artifact in the National Library of the Philippines to give him legal protection and rights to the artifact as his original work.

\subsubsection{Operational Framework}

The system has two sides and these are Administrator side and Employee side. The Administrator side requires validating the user by scanning the fingerprint. The system will 
automatically terminate if it detects three consecutive wrong fingerprints. All the features of the system are accessible to the Administrator account. On the other hand, initiating the Employee side doesn't require validation but recording of employees' attendance needs fingerprint validation. The system will not terminate unless somebody will terminate it.

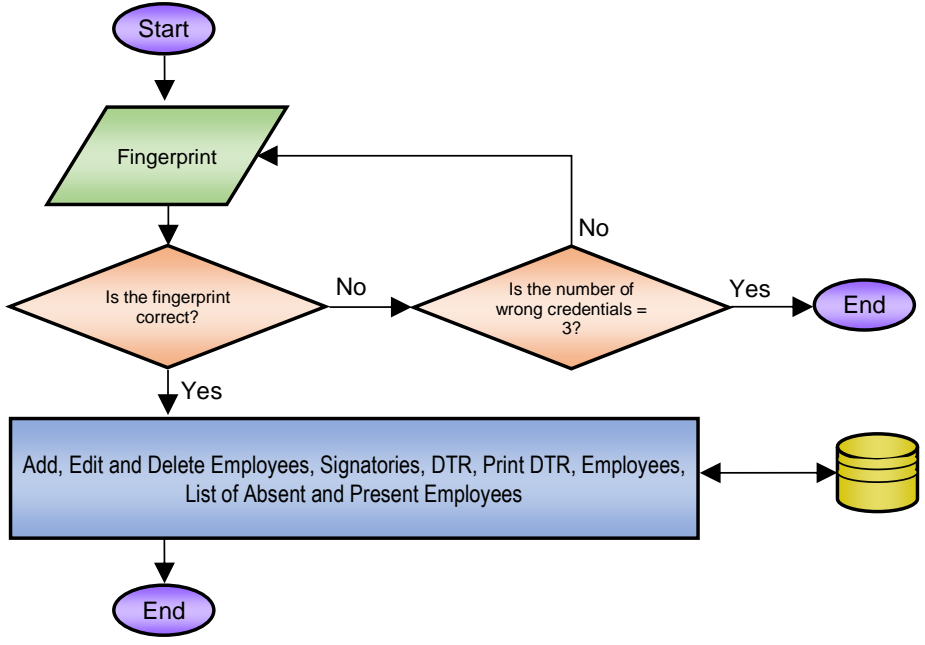

Figure 2: Operational Flowchart of the Administrator Side

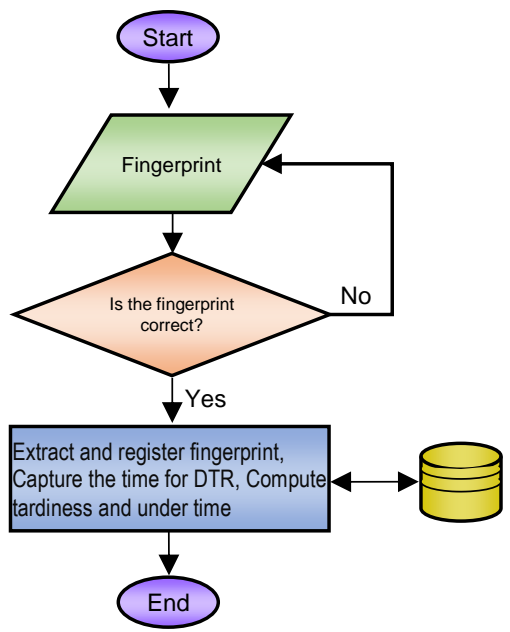

Figure 3: Operational Flowchart of the Employee Side

\subsubsection{Program Structure}

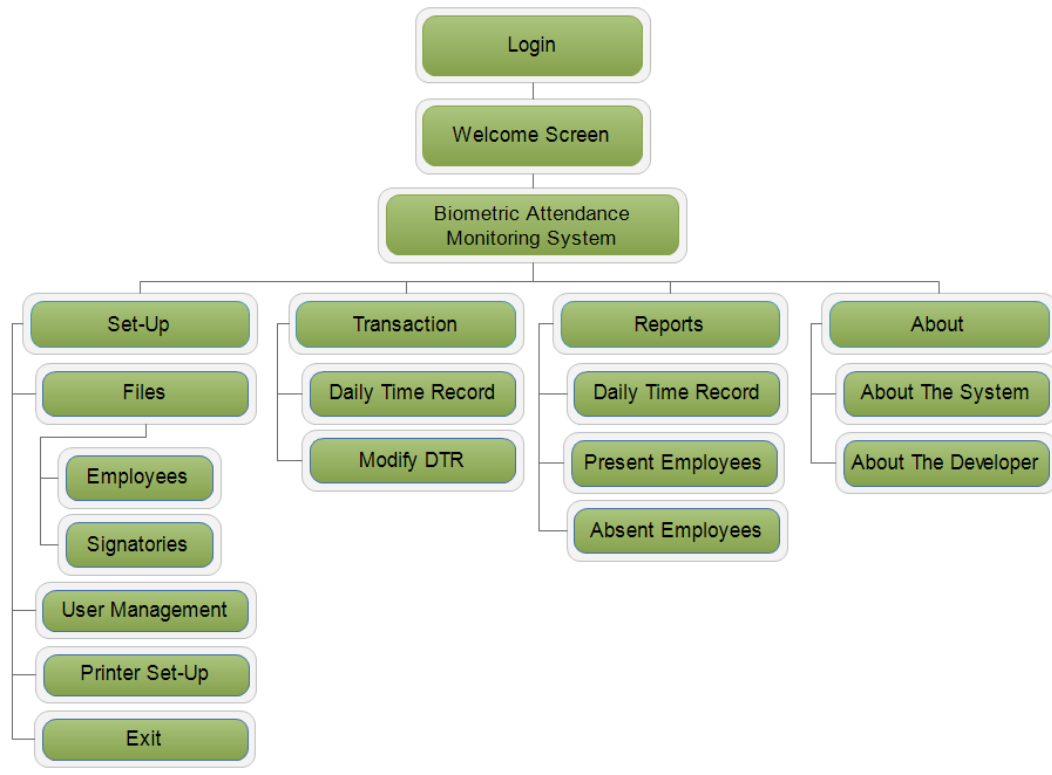

Figure 4: Program Structure of the Administrator Side 


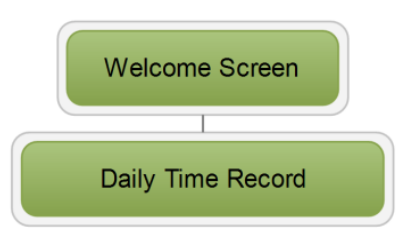

Figure 5. Program Structure of the Employee Side

\subsubsection{Description of the Hardware Components}

a. Computer. This is use to manipulate the system. Windows 7 32-bit OS with 4 GB RAM as sed in the study but older Windows version can also be used to be compatible with the fingerprint reader. A high specification computer unit should be utilized for faster scanning of fingerprint.

b. Fingerprint Reader. This is use to scan and capture fingerprints. Digital Persona U.are.U 4500 Fingerprint Reader was used in the study.

c. Non-impact printers. These are printers that use ink instead of ribbon to print characters on the paper. This is use to print DTR and other reports. Any printer of this kind can be used.

\subsubsection{Software Migration Method}

In deploying the system for operation and production, the researcher applied the Direct Rollout software migration method. Since the system has been tested, the manual system was totally removed and replaced by the BAMS.

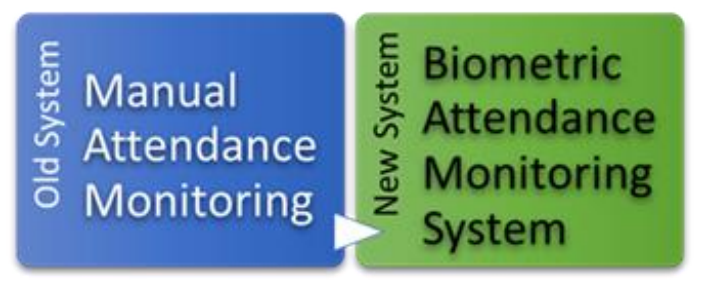

Figure 6: Direct Rollout Migration Method

\subsection{Respondents}

In identifying the problems, the leave card in-charge and some faculty members were the respondents.

\subsection{Measures}

The researcher used interview guides in identifying the problems of the leave card in-charge in monitoring the employees' attendance. Results from the interview were used to identify the features and functionality of the BAMS.

Direct observation was also used before the development of the system to further investigate the problems encountered by the leave card in-charge. This instrument was also used after the system has been deployed for operation. 


\subsection{Procedure}

In conducting the interview, the researcher went to the leave card in-charge to determine the needs and problems in monitoring the employee's attendance. The researcher repeatedly did the same way as data is needed until the completion of the system's features and functionality.

Before the development of the system, the researcher observed how the employees write their time of arrival and departure in the blank Daily Time Record form (CSC Form 48). After the completion and deployment for production or use, the researcher observed the functionality of the system. This is to ensure that the system provides accurate result.

\section{Results and Discussions}

\section{The features of the in-house developed Biometric Attendance Monitoring System}

The following figures show the features, design and the Graphical User Interface (GUI) of the system for the Administrator and Employee Side. The researcher used Visual Basic 6.0 Enterprise Edition programming language as the tool in developing the user interface (front-end) of the system. Likewise, the researcher used Microsoft Access database management system (DBMS) as the tool in developing the database (back-end) of the system.

\section{A. Administrator Side}
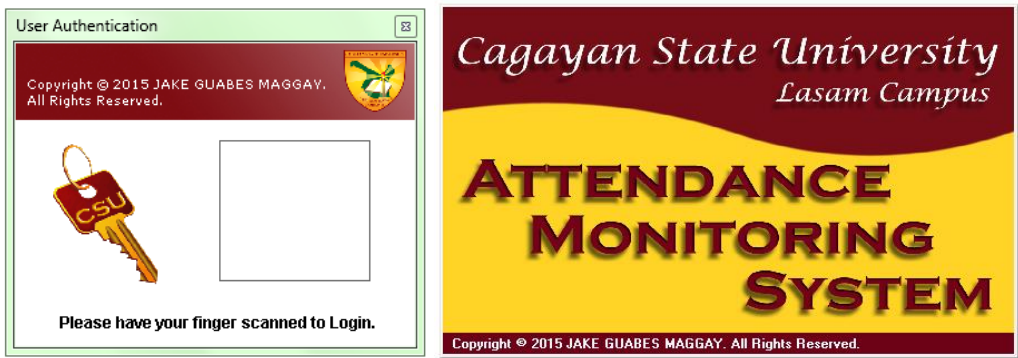

Figure 7: The Login Form and Welcome Screen

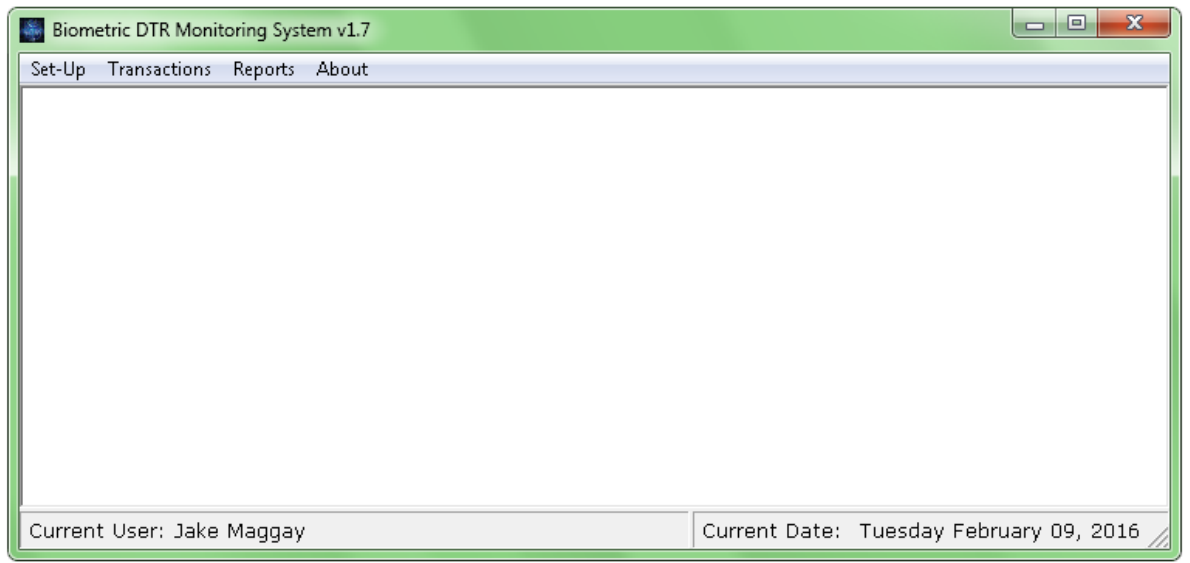

Figure 8: Main Window 


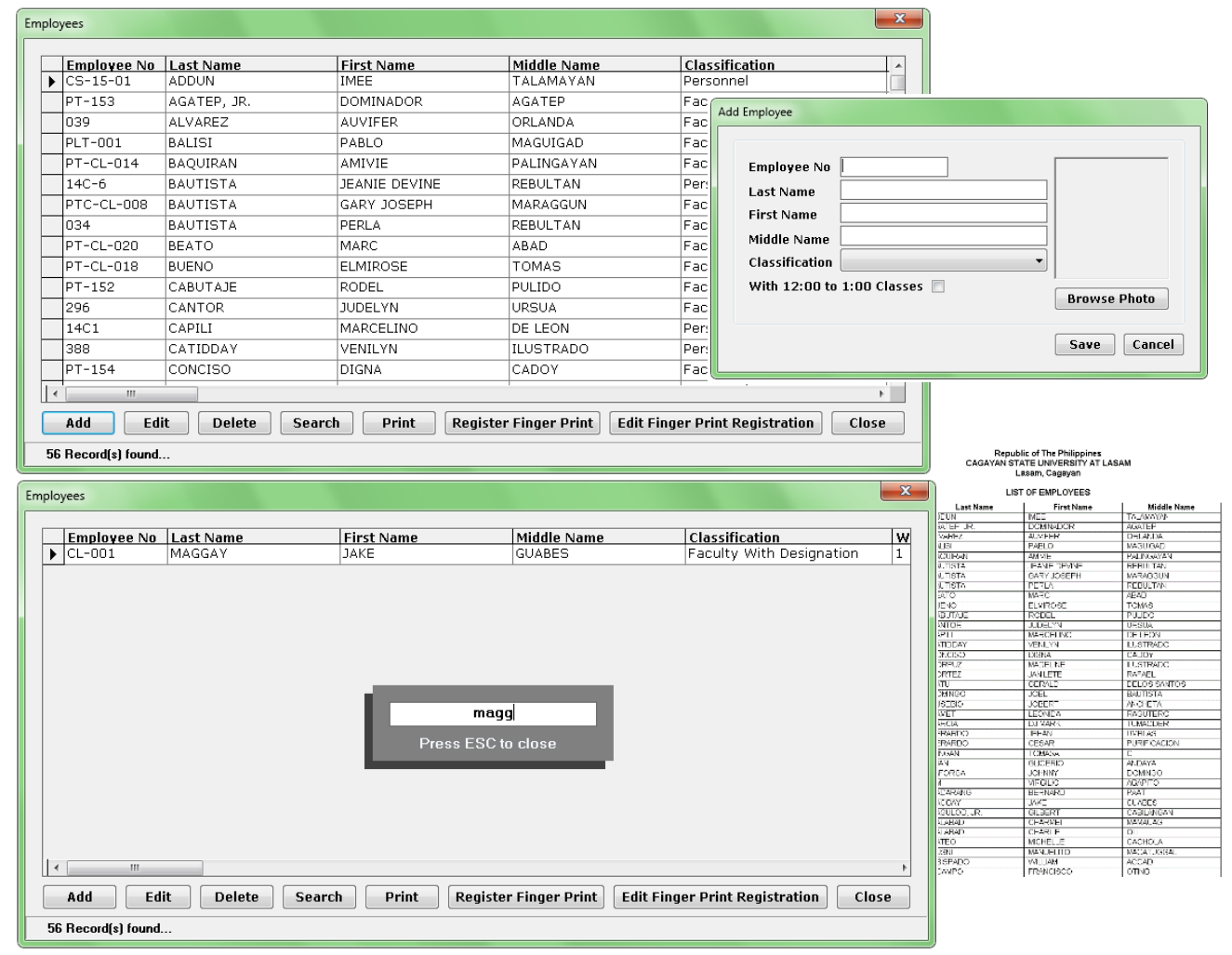

Figure 9: Forms and Report for Employees

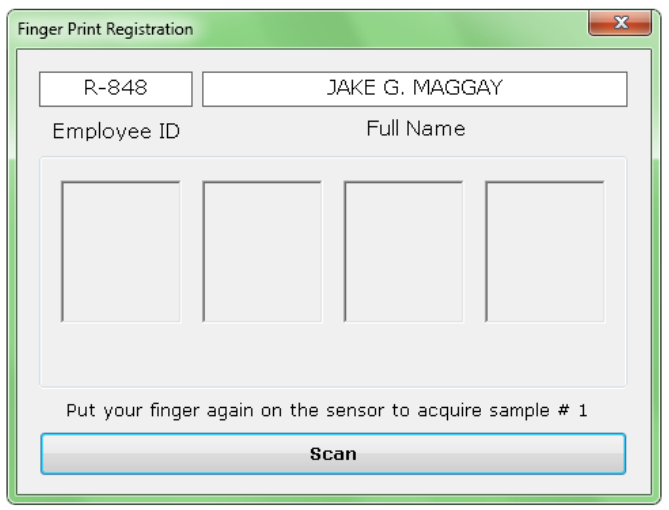

Figure 10: Form for Fingerprint Registration 


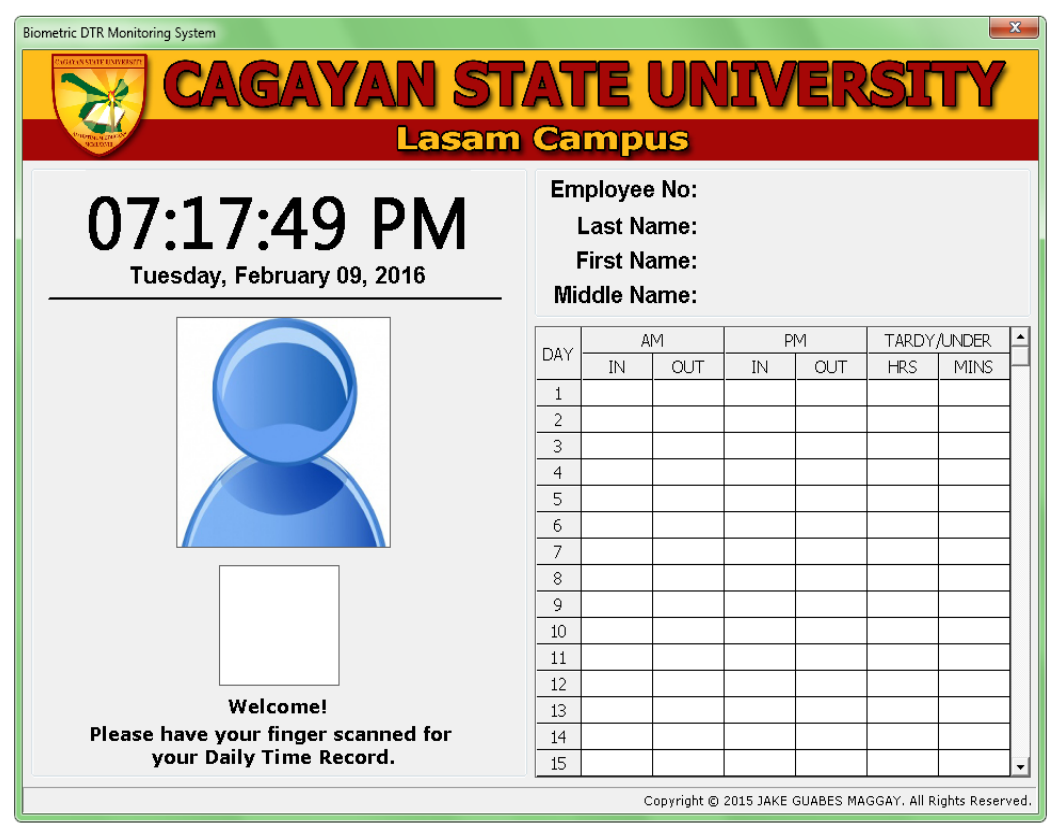

Figure 11: Form for Attendance Monitoring

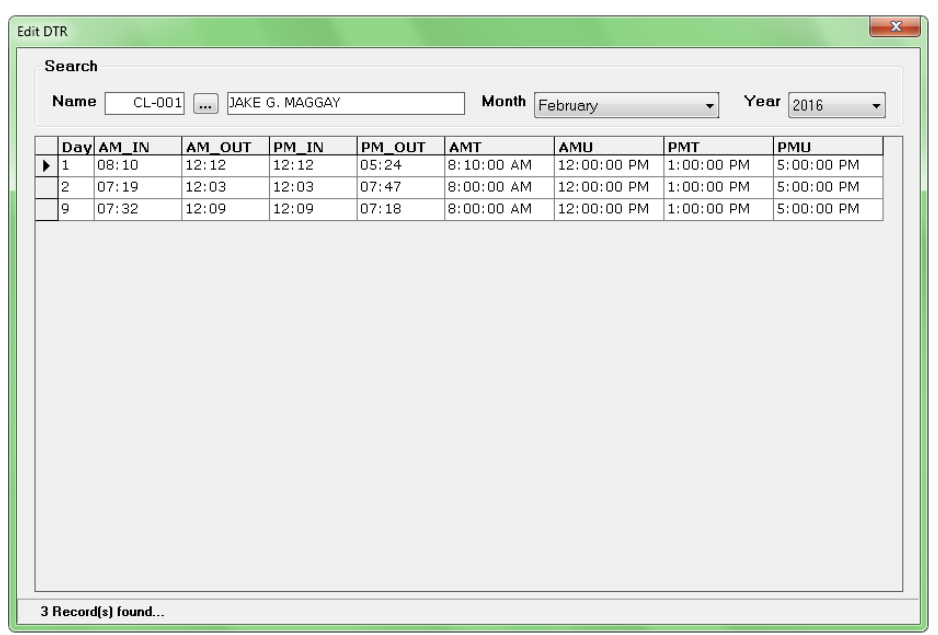

Figure 12: Form for Editing of DTR 

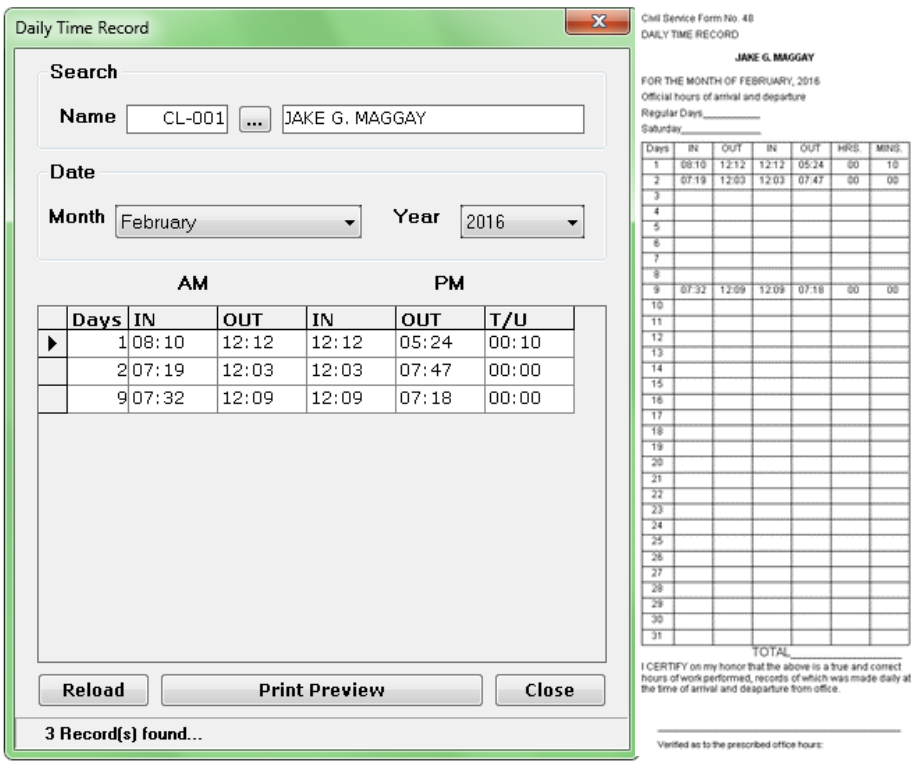

InfoBase Index IBI Factor 3.86

Figure 13: Form and Report for Printing of DTR

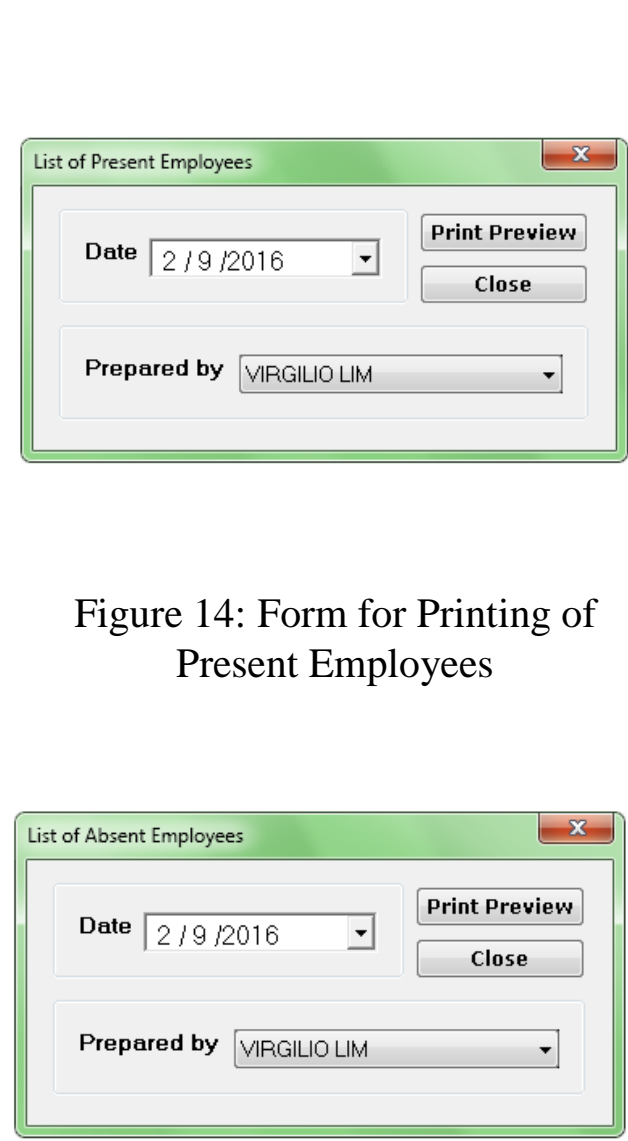

Figure 15: Form for Printing of Absent Employees
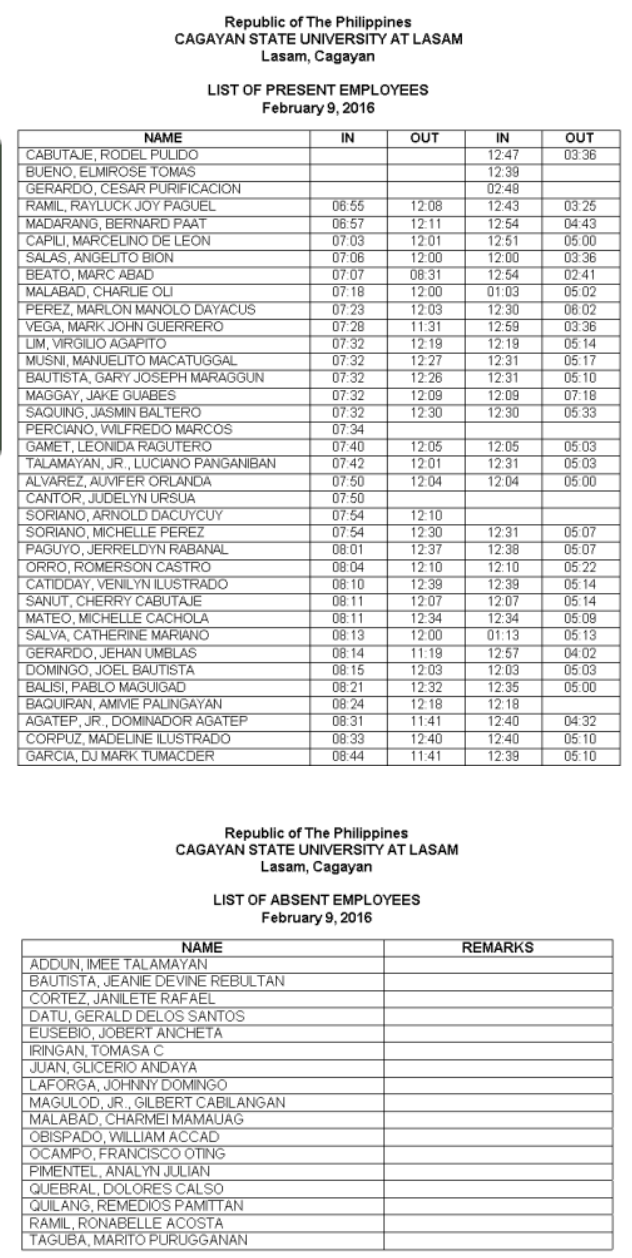

Prepared by.

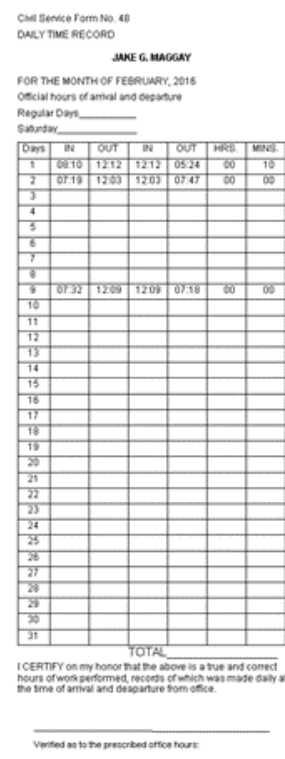




\section{B. Employee Side}

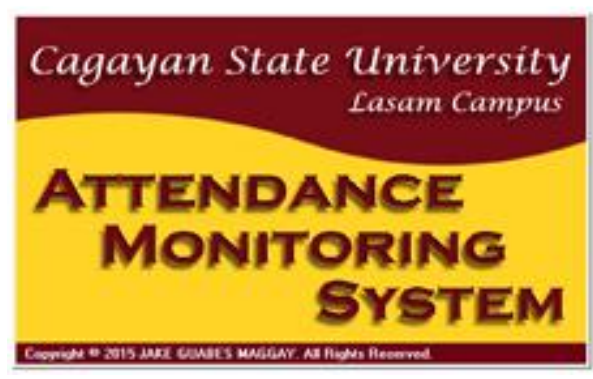

Figure 16: Welcome Screen

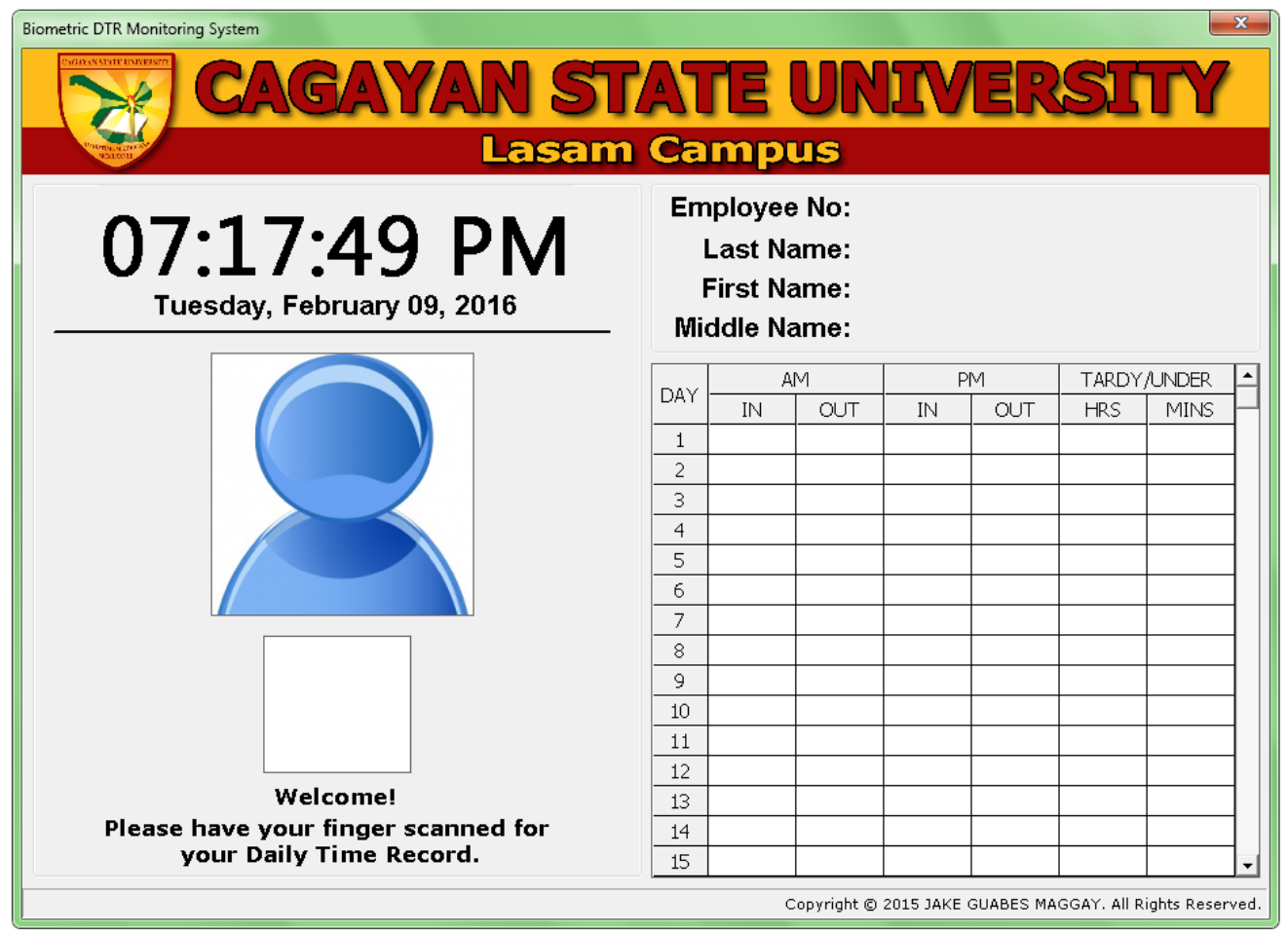

Figure 17: Form for Attendance Monitoring

The Biometric Attendance Monitoring System (BAMS) was deployed and was first used for operation in January 2014. Series of evaluations, revisions and updates were made to achieve its complete functionality. In addition, the manual system has been totally replaced.

The system is secured and it produces reliable output based on the series of tests conducted. Accessing its features requires security, hence, it does not allow unauthorized users to access them. If the Administrator side is launched, the system will require the user to scan the registered finger for fingerprint validation (Figure 18 to 19). The system will automatically terminate if it recognizes three consecutive wrong fingerprints (Figure 20). 


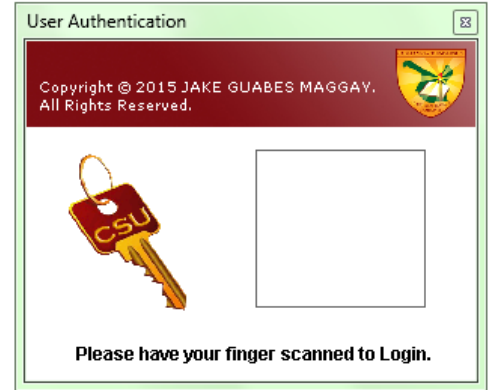

Figure 18: Login form without fingerprint scanned yet

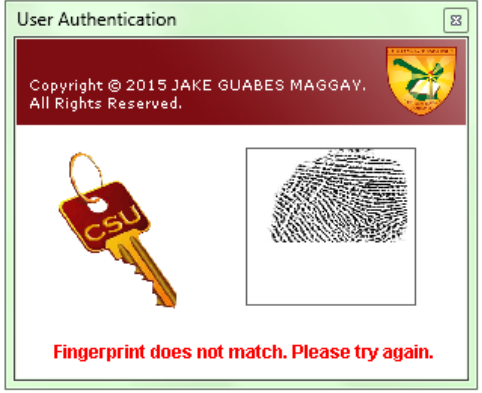

Figure 19: Invalid scanned fingerprint

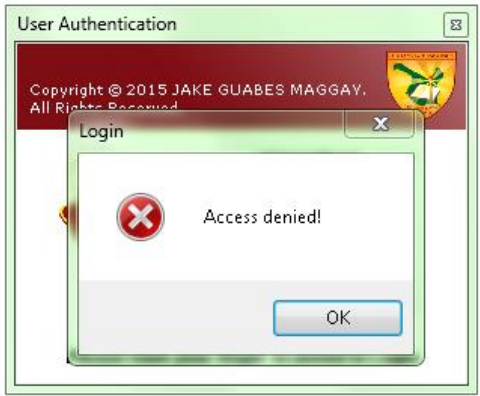

Figure 20: Three consecutive wrong fingerprint

If it recognizes a correct fingerprint, the main widow containing the menus will appear (Figure 8). The user for Administrator account can access all features of the system such as adding, editing and deleting of employees' information and fingerprint, and registration of system users with fingerprint. Editing of DTR in case the employees have accidentally scanned their fingers one minute or more after their recorded arrival time is also accessible. Another is printing of reports such as DTR, list of absent and present employees, and list of employees.

Features in Employee side are intended only to record employees' arrival and departure time and to compute the daily tardiness and under time of each employee. Only registered employees are accepted and allowed in the recording of attendance since the system is using biometric fingerprint reader for validation (Figure 23).

In addition, the system will trap and stop the recording and computation of tardiness and under time if it recognizes an unregistered fingerprint. As part of being user-friendly, the system will inform the user that the scanned fingerprint is not recognized (Figure 21).

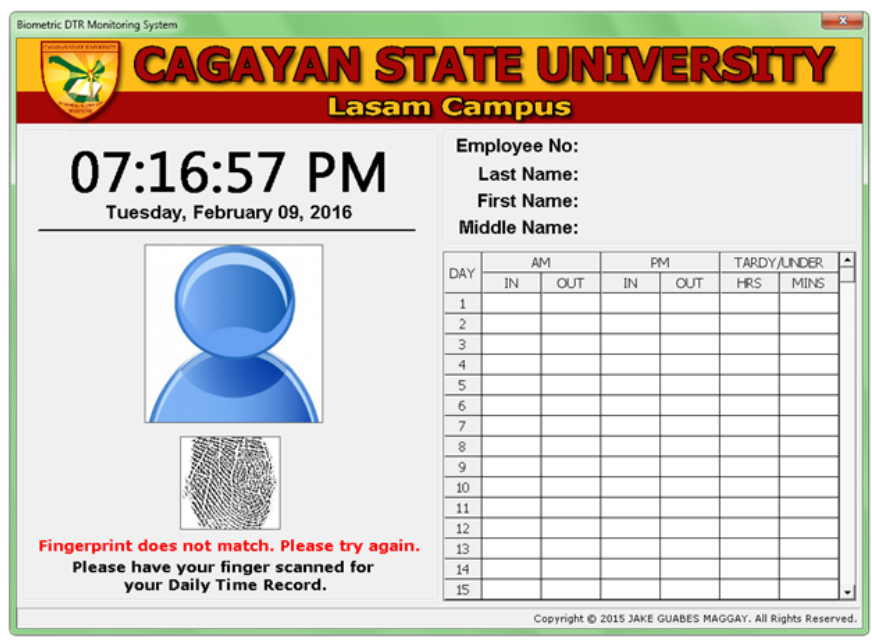

Figure 21: The Employee Side with invalid fingerprint

The system has the capability to control or avoid the recording of departure time that is the same with the arrival time or rescanning the finger to replace the recorded time (Figure 22). 


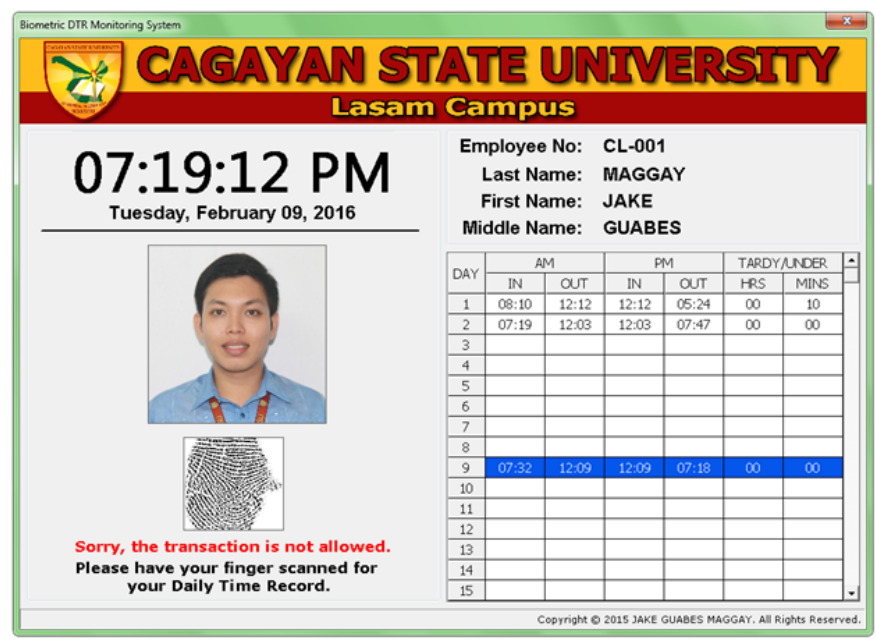

Figure 22: The Employee side with rescanned fingerprint

If the scanned fingerprint is correct, the system will capture the current time of the computer, store it in the database and it will automatically compute the tardiness and under time. The employee cannot alter the time that has been stored in the database since the Administrator side requires fingerprint for user authentication and the Employee side doesn't have this feature. It will likewise display the image, name and the DTR of the employee in the current month. The information will still be displayed in the monitor until another employee replaces it (Figure 23).

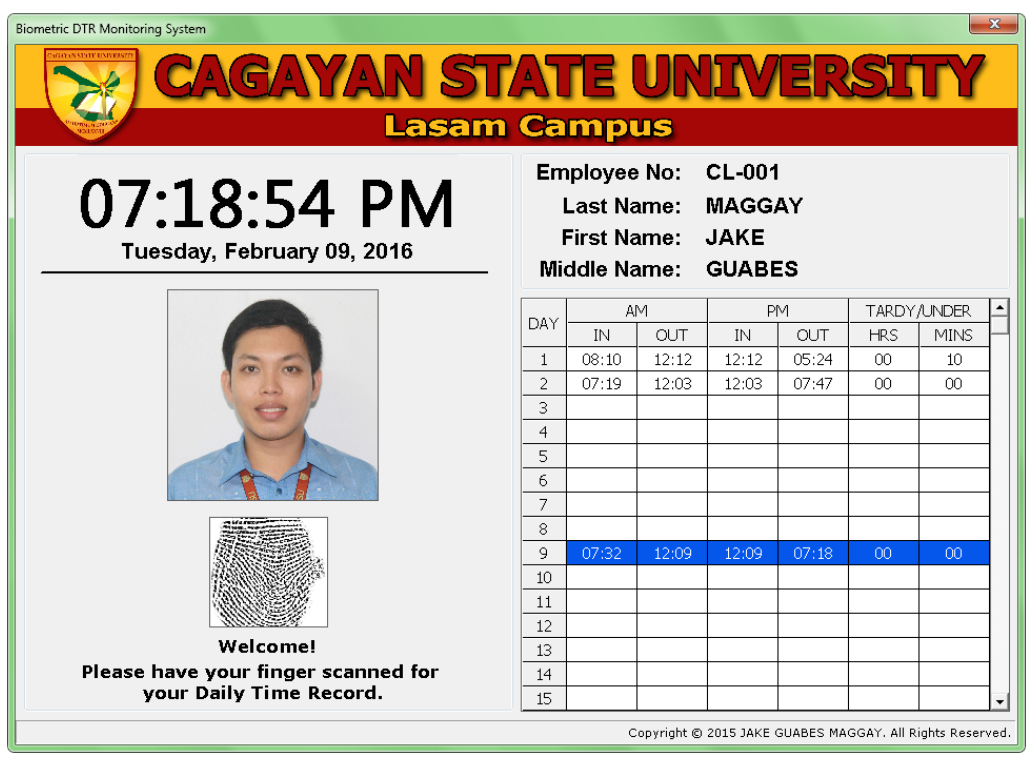

Figure 23: The Employee Side with valid fingerprint

The BAMS can print accurate DTR (Figure 13) using the format prescribed by the Civil Service Commission (Civil Service Form No. 48).

Based on the actual observation, employees became more conscious about their attendance. Some employees are setting an alarm in their mobile phones just to meet the prescribed time integrated in the system. As an effect, employees can serve the clients on time. Likewise, the system also contributes in improving the employees' work values. 


\section{Conclusions \& Recommendations}

\subsection{Conclusions}

The Cagayan State University - Lasam Campus, Philippines (CSU - Lasam) is currently using the Biometric Attendance Monitoring System (BAMS) and basically, the BAMS has many advantages. Securely facilitating the monitoring of employees' attendance is the main advantage of the BAMS, apart from this, the leave card in-charge will no longer compute the daily tardiness and under time of the employees. Likewise, the BAMS gives employees' satisfaction through reliable DTR and accurate computation of tardiness, under time and hours rendered. Furthermore, it will also result to positive economic change through prevention of employees' time theft. As a result, BAMS greatly contributes in providing employees' ease and improving work values. Likewise, it has something to contribute in achieving good governance because it encourages employees to be more punctual.

\subsection{Recommendations}

The BAMS has been successfully developed and deployed. However, it can be improved to have better and more advance application. For future improvement, researcher has the following recommendations:

1) There should be a customized packaging of the BAMS. Instead of using separate computer peripherals such as keyboard, mouse, monitor, system unit (which contains the CPU) and the biometric fingerprint reader, the suggested packaging should be all in one. In addition, you can carry it in a single handling without compromising the features.

2) The BAMS is really helpful in monitoring the attendance of the employees especially for the leave card in-charge; and it gives ease and it lessens the cost from the government, hence, the researcher highly recommends that the system should be maintained and sustained.

\section{Acknowledgements}

I acknowledge the late Prof. Bernardino M. Allag, Jr. for the trust and strong drive in letting me develop the system to contribute in the transformation of the Institution. Also, I thank Dr. Gilbert C. Magulod, Jr. for the commitment, technical expertise and guidance in completing this study. Likewise, my appreciation to the feedback, comments and suggestions of the respondents as input in refining the system's functionality. I also thank my family for the support and motivation to undertake this study.

\section{References}

[1] Salh, G., Mansour, A., Mohammed, M. (2015). Hand Geometric Recognition System based on Support Vector Machines (SVM). Published in International Journal of Advanced Research in Computer and Communication Engineering, Volume 4, Issue 3, IJARCCE 2015, pp. 1. Retrieved February 9, 2016 from http://www.ijarcce.com/upload/2015/march-15/IJARCCE\%20107.pdf

*Corresponding author.

E-mail address: jakegmaggay@gmail.com 